\title{
PEMODELAN PENGARUH SENTIMEN PUBLIK DI TWITTER TERKAIT POLITIK TERHADAP KURS RUPIAH DAN INDEKS HARGA SAHAM DENGAN PENDEKATAN MACHINE LEARNING
}

\author{
(MODELLING EFFECT OF PUBLIC SENTIMENT ABOUT POLITIC IN TWITTER ON RUPIAH \\ EXCHANGE RATE AND STOCK PRICE INDEX WITH MACHINE LEARNING APPROACH)
}

\author{
Epan Mareza Primahendra ${ }^{1}$, Budi Yuniarto \\ Politeknik Statistika STIS ${ }^{1}$ \\ Politeknik Statistika STIS ${ }^{2}$ \\ Banyuasin, Sumatera Selatan \\ E-mail: epanmareza07@gmail.com
}

\begin{abstract}
ABSTRAK
Kurs Rupiah dan indeks harga saham (IHS) berpengaruh terhadap perekonomian Indonesia. Pergerakan kurs Rupiah dan IHS dipengaruhi oleh informasi publik, kondisi sosial, dan politik. Kejadian politik banyak menimbulkan sentimen dari masyarakat. Sentimen tersebut banyak disampaikan melalui media sosial terutama Twitter. Twitter merupakan sumber big data yang jika datanya tidak dimanfaatkan akan tidak berguna. Pengumpulan data dilakukan pada periode 26 September 2019 - 27 Oktober 2019. Pola jumlah tweets harian yang sesuai dengan pergerakan kurs Rupiah dan IHS mengindikasikan bahwa terdapat hubungan antara sentimen di Twitter terkait situasi politik terhadap kurs Rupiah dan IHS. Penelitian ini menggunakan pendekatan machine learning dengan algoritma Neural Network dan Least Square Support Vector Machine. Penelitian ini bertujuan untuk mengetahui pengaruh sentimen terhadap kurs Rupiah dan IHS sekaligus mengkaji kedua algoritmanya. Hasilnya menjelaskan bahwa model terbaik untuk estimasi IHS yaitu NN dengan 1 hidden layer dan 2 hidden neurons. Modelnya menunjukan bahwa terdapat pengaruh antara sentimen tersebut terhadap IHS karena volatilitas estimasi IHS sudah cukup mengikuti pola pergerakan IHS aktual. Model terbaik untuk estimasi kurs Rupiah yaitu LSSVM. Pola pergerakan estimasi kurs Rupiah cenderung stagnan di atas nilai aktual. Ini mengindikasikan bahwa modelnya masih belum memuaskan dalam mengestimasi pengaruh sentimen publik terhadap kurs Rupiah.
\end{abstract}

Kata kunci: analisis sentimen, politik, regresi, neural network, LSSVM

\begin{abstract}
Rupiah exchange rate and stock price index have a significant impact on Indonesian economy. Its movement influenced by public information, social condition, and politics. Political events evoke many public sentiments. Those public sentiments delivered on social media especially Twitter. Twitter is a big data sources which if it hasn't utilized, it will be useless. Data collection already started from 26 September 2019-27 October 2019. Number of tweets in each day has produce a same pattern on Rupiah exchange rate and stock price index. It can indicate that those tweets on politics situation have correlation with Rupiah exchange rate and stock price index. This research used machine learning approach with Neural Network and Least Square Support Vector Machine. This research aims to know about correlation on public sentiments towards Rupiah exchange rate and stock price index and also to compare both algorithms. The results explain that the best model on estimate stock price index is NN with 1 hidden layer and 2 hidden neurons. Model is showing that there a correlation public sentiment on Twitter towards stock price index because stock price index estimation volatility has same pattern with actual stock price index. The best model on estimate Rupiah exchange rate is LSSVM. Rupiah exchange rate's estimation movement pattern is stagnant above the actual. It indicates that its model isn't satisfying on estimating public sentiments towards Rupiah exchange rate.
\end{abstract}


Keywords: sentiment analysis, politics, regression, neural network, LSSVM

\section{PENDAHULUAN}

Perekonomian Indonesia merupakan salah satu tolak ukur keberhasilan kinerja pemerintah. Indikator pendukung yang memengaruhi perekonomian Indonesia seperti pertumbuhan ekonomi, nilai tukar Rupiah, dan kapitalisasi pasar saham. Ketiga indikator tersebut saling memengaruhi satu sama lain. Nilai tukar atau kurs merupakan harga nilai mata uang terhadap mata uang negara lain. Nilai tukar mata uang sangat penting dalam proses perdagangan antar negara karena memegang peranan dalam menerjemahkan harga dari berbagai negara ke dalam satu bahasa yang sama (Ekananda, 2014:168). Fluktuasi nilai tukar Rupiah dipengaruhi oleh sentimen pasar atau berita politik yang mana dapat memengaruhi permintaan dan penawaran devisa yang mengakibatkan pergerakan harga nilai tukar menjadi terapresiasi atau terdepresiasi (Madura dan Fox, 2011:108).

Begitupun dengan pasar saham, sebagai sumber pendanaan kebutuhan perusahaan berimplikasi pada perekonomian Indonesia karena pasar saham meningkatkan pendapatan negara. Oleh karena itu, perlunya pengamatan dengan cara estimasi indeks harga saham agar pemerintah atau pihak terkait dapat memerhatikan kejadian-kejadian yang berpengaruh pada naik turunnya harga saham. Menurut Pradhypta et.al (2018), pergerakan harga saham dipengaruhi oleh informasi publik, kebijakan makroekonomi, kondisi sosial, kondisi politik suatu negara, dan lainlain.

Politik merupakan tema yang selalu ramai diperbincangkan. Mulai dari masyarakat biasa hingga pemegang kekuasaan. Umumnya berisi pujian ataupun kritik terhadap pemerintahan. Periode 26 September 2019 hingga 27 Oktober 2019, terjadi beberapa kejadian politik di Indonesia seperti pasca demonstrasi terkait revisi UU KPK dan RUU KUHP pada akhir September 2019 hingga awal Oktober 2019, pelantikan presiden Indonesia tanggal 20 Oktober 2019, dan pengumuman kabinet tanggal 23 Oktober 2019. Kejadian tersebut menimbulkan beragam sentimen dari masyarakat. Pada periode itu, keadaan kurs Rupiah dan indeks harga saham juga menunjukan pergerakan yang signifikan. Hal ini mengindikasikan bahwa kejadian politik tersebut memengaruhi nilai tukar Rupiah dan indeks harga saham. Sentimen politik dapat menjadi sebab yang mengakibatkan pergerakan nilai tukar Rupiah dan harga saham. Media yang banyak digunakan oleh masyarakat untuk menyampaikan sentimen terkait politik di Indonesia yaitu media sosial.

Media sosial merupakan salah satu media yang bersifat terbuka dan tak terbatas. Setiap orang dapat menggunakannya tanpa ada batasan sedikitpun termasuk terkait politik. Berdasarkan data yang dirilis oleh Asosiasi Penyelenggara Jasa Internet Indonesia (APJII), pengguna internet di Indonesia mengalami kenaikan dari tahun 2017 yang hanya sebesar 143,26 Juta menjadi 171,17 Juta pada tahun 2018 (Merdeka.com, 2019). Sementara untuk pengguna media sosial di Indonesia mencapai 150 Juta pengguna aktif dan 130 Juta diantaranya pengguna aktif melalui mobile. Salah satu media sosial yang paling banyak digunakan yaitu Twitter.

Twitter merupakan layanan online microblogging. Twitter dapat digunakan untuk mengekspresikan diri dan menyampaikan pendapat. Selain sebagai online microblogging, Twitter digunakan oleh peneliti sebagai sumber data penelitian karena mudah dan cepatnya dalam mengaplikasikan Application Programming Interface (API). Sebagai sumber data untuk analisis sentimen, peneliti tidak perlu khawatir dengan partisipan yang lupa terhadap suatu kejadian (Ahmed W et. al. 2017). Banyaknya masyarakat yang memberikan sentimen di Twitter terkait kejadian politik dapat menjadi salah satu kemungkinan sumber data dalam mengestimasi naik turunnya nilai tukar Rupiah dan indeks harga saham. Sehingga pemerintah dan pihak terkait dapat lebih bersiap dalam mengatasi dan mempertahankan naik turunnya nilai tukar Rupiah dan indeks harga saham.

Rata-rata terdapat 332 Juta pengguna Twitter per bulan dengan jumlah tweets sekitar 500 juta per hari dan 200 miliar tweets setiap tahunnya. Pada tahun 2015, jumlah pengguna Twitter di Indonesia mencapai 50 Juta pengguna (CNN Indonesia, 2016). Berdasarkan data pengguna Twitter tersebut tentunya akan menghasilkan banyak data unstructured yang dihasilkan oleh tweets. Pertumbuhan data yang sangat cepat, volume yang sangat besar, dan format data yang 
beragam menandakan bahwa data Twitter merupakan salah satu sumber big data. Data unstructured tersebut hanya akan menjadi kumpulan data tidak berguna ketika tidak dimanfaatkan.

Pemanfaatan big data unstructured dapat diatasi dengan penggunaan machine learning karena dapat membantu menemukan model terbaik tanpa harus mengandalkan rules- based programming. Berbeda dengan regresi yang harus memenuhi beberapa asumsi klasik. Pada dasarnya, machine learning mengasumsikan beberapa asumsi, tetapi secara umum penggunaan machine learning terhindar dari sebagian besar asumsi tersebut (Srivastava, 2015). Pemanfaatan data unstructured dalam pemodelan tentunya berguna dalam melengkapi variabel untuk pengamatan dan meminimalkan error estimasi nilai tukar Rupiah dan indeks harga saham. Selain itu, pemodelan ini juga ingin mengetahui seberapa besar sentimen publik di Twitter terkait politik dapat memengaruhi nilai tukar Rupiah dan indeks harga saham. Oleh karena itu, dilakukan penelitian terkait pemodelan pengaruh sentimen publik di Twitter terkait situasi politik terhadap nilai tukar Rupiah dan indeks harga saham dengan pendekatan machine learning.

\section{METODE}

\section{Metode Pengumpulan Data}

Pada penelitian ini, data terbagi menjadi variabel dependen dan variabel independen. Data variabel dependen yaitu kurs tengah nilai tukar Rupiah dan indeks harga saham. Nilai tukar rupiah diperoleh dengan mengunduh kurs jual dan kurs beli dari website bank Indonesia. Setelah itu, dihitung kurs tengah dengan persamaan sebagai berikut:

$$
\text { Kurs Tengah }=\frac{\text { Kurs Jual+Kurs Beli }}{2} \text {..... }
$$

Sedangkan indeks harga saham diperoleh dari Indonesia stock exchange. Indeks harga saham yang digunakan yaitu Indeks Harga Saham Gabungan (IHSG) dan indeks harga saham LQ45.

Sedangkan untuk variabel independen menggunakan data Twitter. Data Twitter dikumpulkan melalui streaming API Twitter dengan package tweepy pada periode 26 September 2019 hingga 27 Oktober 2019. Proses streaming API Twitter menggunakan beberapa kata kunci dan hashtag. Penentuan kata kunci ditentukan oleh peneliti berdasarkan hashtag atau kata kunci yang ramai diperbincangkan. Data Twitter yang telah dikumpulkan dilakukan analisis lebih lanjut untuk mengetahui model terbaik dalam pemodelan pengaruh sentimen publik terkait situasi politik di Twitter terhadap nilai tukar Rupiah dan indeks harga saham.

\section{Metode Analisis}

Peneliti melakukan beberapa metode analisis untuk mendapatkan hasil yang diharapkan. Adapun tahapan analisis akan dijelaskan sebagai berikut:

1. Imputasi data sekunder

Nilai tukar Rupiah dan indeks harga saham selalu tidak tersedia pada hari Sabtu, Minggu, dan hari libur nasional. Hal itu menyebabkan missing values. Oleh karena itu digunakan concave function atau metode cekung sebagai metode imputasi (Mittal dan Goel, 2011).

$$
x_{+1}=\frac{y+x}{2}
$$

Tabel 1. Ilustrasi Imputasi Data Nilai Tukar Rupiah

\begin{tabular}{ccccc}
\hline Tanggal & Kurs Rupiah & Imputasi 1 & Imputasi 2 & Kurs Lengkap \\
\hline 18 Oktober 2019 & 14140 & & & 14140 \\
19 Oktober 2019 & & 14136 & \multirow{2}{*}{14134} & 14136 \\
20 Oktober 2019 & & & & 14134 \\
21 Oktober 2019 & 14132 & & 14132 \\
\hline
\end{tabular}

\section{Text preprocessing untuk data Twitter}

Text preprocessing adalah suatu proses dalam text mining yang bertujuan mengekstraksi suatu teks guna mendapatkan pengetahuan dan informasi menarik dari sebuah data teks yang tidak terstruktur (Kannan dan Gurusamy, 2014). Data teks Twitter perlu dilakukan text 
preprocessing. Tahapan text preprocessing yang dilakukan dalam penelitian ini adalah sebagai berikut:

a) Lexical analysis seperti menghapus username, hashtag, tanda baca, angka, dan white spaces

b) Normalisasi menjadi kata baku

c) Menghapus kata imbuhan (stemming) dan removal stopwords menggunakan library sastrawi

d) Menghapus baris yang hanya terdapat string kosong

e) Melakukan pemecahan kalimat menjadi kata (tokenisasi).

Proses text preprocessing membutuhkan waktu yang lama dan sulit karena harus memastikan bahwa data sudah cukup baik untuk dilakukan analisis lanjutan.

\section{Analisis Sentimen}

Proses analisis sentimen menggunakan pendekatan berbasis lexicon. Kamus yang digunakan merupakan kamus dari hasil penelitian (Wahid dan Azhari, 2016). Kamusnya berisi nilai polaritas dari -5 hingga 5 yang ditentukan oleh 3 ahli linguistik. Proses analisis sentimen melakukan pencocokan kata pada tweets dengan kata pada kamus. Tweets dengan skor polaritas $>0$ akan diklasifikasikan menjadi sentimen positif, skor polaritas < 0 menjadi sentimen negatif, dan skor polaritas $=0$ menjadi sentimen netral. Selain kamus sentimen, ada kamus negasi dan boosterwords. Kamus boosterwords digunakan untuk meningkatkan atau mengurangi nilai polaritas. Misal kata 'sangat pintar' akan memiliki nilai polaritas lebih tinggi dibandingkan kata 'pintar' ataupun 'kurang pintar'. Sementara kamus negasi digunakan untuk mengubah nilai polaritas. Misal skor pada sebuah tweets -7 maka ketika ada kata yang terdapat dalam kamus negasi akan mengubah skor menjadi 7.

\section{Analisis Korelasi}

Hasil klasifikasi pada analisis sentimen akan menjadi kemungkinan variabel independen dalam pemodelan. Analisis korelasi digunakan untuk mengetahui hubungan antar variabel dan menentukan variabel independen yang akan digunakan. Hasil korelasi tertinggi akan menjadi variabel independen dalam pemodelan. Kemungkinan variabel independen yang digunakan yaitu jumlah tweets, jumlah positif, jumlah negatif, jumlah netral, dan rasio negatif terhadap positif. Variabel dengan korelasi ( $\boldsymbol{\rho}$ ) paling tinggi akan digunakan dalam penelitian. Analisis korelasi yang digunakan yaitu korelasi rank spearman karena tidak didasari pada asumsi distribusi populasi.

\section{Uji linieritas}

Uji linieritas menggunakan analisis Ramsey Reset Test. Uji ini digunakan untuk mengetahui kelinieran dari data. Hasil dari analisis ini digunakan sebagai informasi tambahan untuk menentukan algoritma dan kernel pemodelan yang sesuai. Reset Test didasari pada prinsip lagrange multiplier dan dijalankan menggunakan critical values dari distribusi $\mathrm{F}$.

\section{Standardisasi}

Standardisasi dilakukan untuk menghindari dampak dari berbagai macam skala yang berbedabeda. Skala berbeda berdampak pada weighting yang salah. Metode standarisasi yang digunakan yaitu min max normalization. Min max normalization dapat diformulasikan sebagai berikut:

$$
a^{\prime}=\frac{a-\min \left\{a_{i}\right\}}{\max \left\{a_{i}\right\}-\min \left\{a_{i}\right\}} \text {. }
$$

\section{Pemodelan regresi}

Pemodelan menggunakan algoritma Least Square Support Vector Machine (LSSVM) dan Artificial Neural Network (ANN). Pemodelan tersebut berguna untuk mengestimasi dan melihat pengaruh dari variabel terpilih terhadap data sekunder berdasarkan kejadian politik yang terjadi. Dalam pemodelan ini, data dibagi menjadi data latih dan data uji. Perbandingan pembagian data menjadi $75 \%$ untuk data latih dan $25 \%$ untuk data uji. Data latih dimulai dari tanggal 26 September 2019-19 Oktober 2019. Sedangkan data uji dimulai dari tanggal 20 Oktober 2019hingga 27 Oktober 2019. Dalam proses training, dilakukan evaluasi algoritma dengan menggunakan 10 -fold cross validation agar model yang didapat tidak terjadi overfitting dan dapat mengurangi waktu komputasi.

Algoritma LSSVM yang digunakan menggunakan kernel radial. Sedangkan algoritma neural network menggunakan algoritma pembelajaran backpropagation dan fungsi aktivasi sigmoid. Pada penelitian ini, terdapat 3 kombinasi hidden layer dan hidden neuron yang akan digunakan, seperti 
1 hidden layer dan 1 hidden neuron (1/1/1), 2 hidden layer dan masing-masing 1 hidden neuron $(1 / 1 / 1 / 1)$, dan 1 hidden layer dan 2 hidden neurons (1/2/1). Sehingga terdapat 4 model untuk setiap variabel dependen yang akan dilakukan pemodelan yaitu 1 model LSSVM dan 3 model NN. Model terbaik dipilih berdasarkan hasil evaluasi dari estimasi yang dilakukan terhadap data uji.

\section{Metode Evaluasi}

Metode evaluasi yang digunakan yaitu mean absolute percentage error (MAPE) dan root mean square error (RMSE). MAPE adalah nilai persentase dari rata-rata kesalahan absolut pada nilai hasil estimasi dengan nilai asli pada suatu periode tertentu. RMSE adalah akar dari nilai kuadrat kesalahan estimasi dari suatu model terhadap nilai sebenarnya. Semakin kecil nilai RMSE dan MAPE maka semakin baik dan akurat juga hasil estimasi dari model tersebut.

\section{HASIL DAN PEMBAHASAN}

\section{Deskripsi Data dan Text Preprocessing}

Pada periode 26 September 2019-27 Oktober 2019, terlihat bahwa indeks harga saham dan nilai tukar Rupiah mengalami fluktuasi dan memiliki pola yang sama. Pada akhir September 2019 hingga awal Oktober 2019, indeks harga saham melemah dan nilai tukar Rupiah cenderung datar yang mana pada periode tersebut merupakan pasca terjadinya demonstrasi mahasiswa. Sedangkan pasca pelantikan presiden Indonesia, indeks harga saham dan nilai tukar Rupiah mulai mengalami penguatan dan puncaknya terjadi pasca pengumuman kabinet Indonesia Maju 20192024.
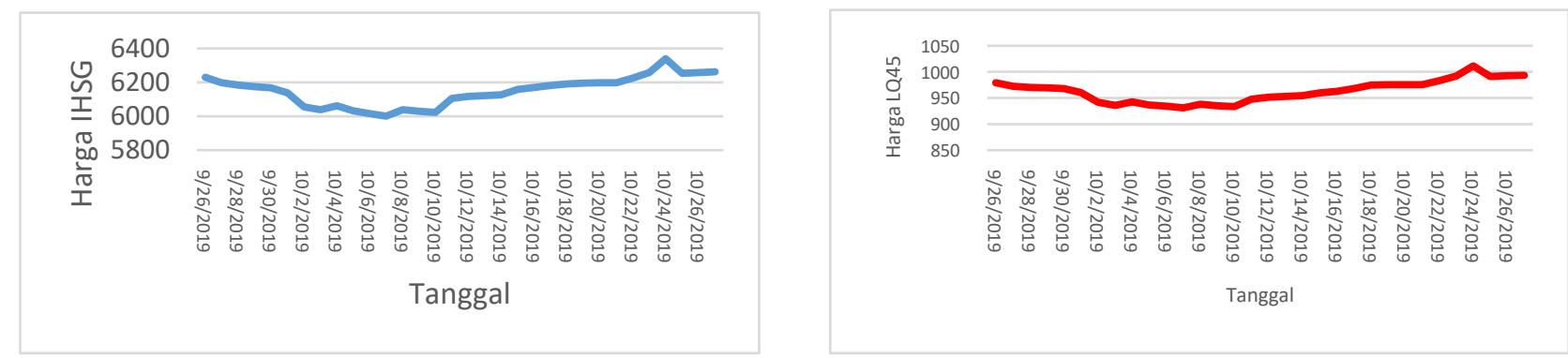

Gambar 1. Grafik Indeks Harga Saham Gabungan dan Indeks Harga Saham LQ45

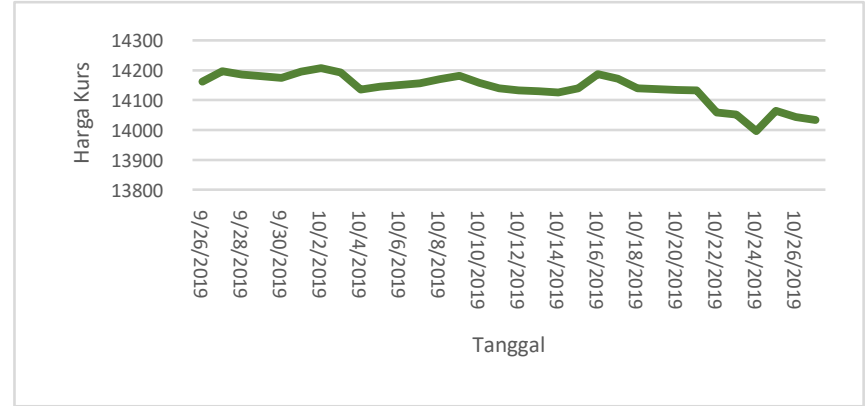

Gambar 2. Grafik Nilai Tukar Rupiah

Pasca demonstrasi mahasiswa tidak terlalu memberikan pengaruh yang signifikan terhadap nilai tukar Rupiah. Itu dapat dilihat dari grafik yang cenderung datar dan tidak ada lonjakan yang signifikan. Sedangkan pasca pelantikan presiden, kurs Rupiah juga terjadi penguatan.

Jumlah data Twitter yang baru dikumpulkan sebesar 1,9 juta tweets. Masih banyak tweets yang kosong, berisi bahasa yang tidak baku, berisi singkatan, dan lain-lain. Data yang tidak dilakukan text preprocessing berakibat pada tidak dapat diekstraknya informasi secara langsung. Misal, kata 'pintar!' atau 'bdh' tidak akan ditemukan di kamus sehingga kata tersebut tidak akan memiliki nilai polaritas. Akibatnya hasil analisis sentimen akan semakin bias. Oleh karena itu, perlunya dilakukan text preprocessing. Data Twitter dilakukan text preprocessing agar datanya menjadi lebih terstruktur sehingga lebih mudah untuk diolah dan dianalisis. Tahapan text preprocessing merupakan tahapan yang paling sulit dan lama karena peneliti harus memastikan bahwa data yang digunakan sudah baik untuk dilakukan analisis. Text preprocessing juga 
berfungsi menghilangkan noise agar datanya lebih berkualitas. Berikut ini beberapa contoh hasil text preprocessing.

Tabel 2. Data Twitter Sebelum Text Preprocessing

\begin{tabular}{ll}
\hline No & \multicolumn{1}{c}{ Tweet } \\
\hline 1 & Tujuan pak jokowi dan hanya allah swt yang bisa melindungi pak jokowi ... smoga semua baik2 saja \\
2 & Negara kita jadi bangkrut dong pakde??? \\
3 & Buzzer2nya jokowi bisa diem aja ga sih anjir, ga pegel apa ngejilat mulu ? \\
4 & @jokowi @MndJaya Setuju Bu Susi jadi menteri Lingkungan Hidup \#SusiForLHK karena pencegahan \\
& $\begin{array}{l}\text { lebih baik daripada penindakan tanpa investigasi akar permasalahan. Investor lari dan phk masal } \\
\text { terjadi. Prestasi Wasit Bola bukan karena jumlah kartu merah dan kuning yg dihasilkan. }\end{array}$ \\
5 & Nyobain dagangan anak presiden ? @kaesangp https://t.co/sjbidNxMvL \\
\hline
\end{tabular}

Tabel 3. Data Twitter Setelah Text Preprocessing

\begin{tabular}{cl}
\hline No & \\
\hline 1 & jokowi hanya allah swt lindung jokowi moga baik \\
2 & negara bangkrut pakde \\
3 & buzzer jokowi diam tidak sih anjing tidak gel jilat melulu \\
4 & bu sus menteri lingkung hidup cegah lebih baik tindak investigasi akar masalah investor lari putus \\
& hubung masal prestasi wasit bola kartu merah kuning hasil \\
5 & nyobain dagang anak presiden
\end{tabular}

Setelah dilakukan text preprocessing, tweets tereduksi sekitar 200 ribu tweets menjadi 1,7 juta tweets. Pengurangan jumlah tweets terbanyak di tanggal 20 Oktober 2019 dengan 20.660. Sedangkan pengurangan paling sedikit terjadi tanggal 30 September 2019 dengan 3.816 tweets.

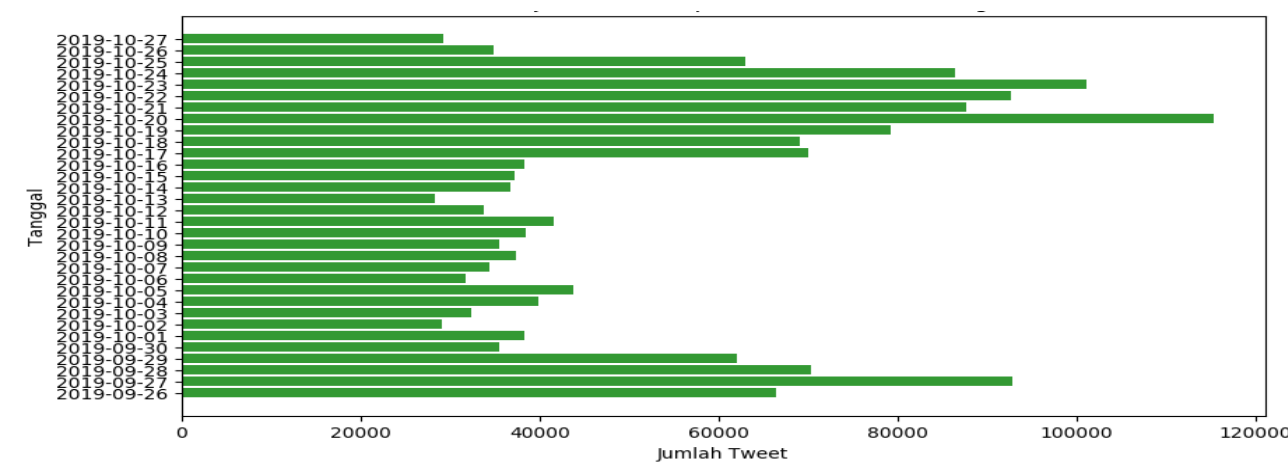

Gambar 3. Grafik Jumlah Tweets Pada 26 September 2019-27 Oktober 2019 pengurangan jumlah tweets disebabkan karena banyaknya pengguna yang melakukan tweets dengan isi duplikat. Hal itu bisa disebabkan karena adanya buzzer atau beberapa orang yang ingin mendukung pemerintahan maupun tidak mendukung pemerintahan. Hal itu terjadi karena suasana politik pada periode penelitian tersebut yang masih sangat terasa.

\section{Analisis Sentimen}

Analisis sentimen dilakukan dengan berbasis kamus. Berikut beberapa contoh hasil analisis sentimen dan nilai polaritasnya.

Tabel 4. Total Skor Hasil Analisis Sentimen

\begin{tabular}{clcc}
\hline No & \multicolumn{1}{c}{ Tweet } & Sentimen & Total Skor \\
\hline 1 & ['jokowi', 'hanya', 'allah', 'swt', 'lindung', 'jokowi', 'moga', 'baik'] & Positif & 4 \\
2 & ['negara', 'bangkrut', 'pakde'] & Negatif & -5 \\
3 & ['buzzer', 'jokowi', 'diam', 'tidak', 'sih', 'anjing', 'tidak', 'gel', 'jilat', 'melulu'] & Negatif & -10 \\
4 & ['bu', 'sus', 'menteri', 'lingkung', 'hidup', 'cegah', 'lebih', 'baik', 'tindak', & Positif & 3 \\
& 'investigasi', 'akar', 'masalah', ''investor', 'lari', 'putus', 'hubung', 'masal', & & \\
& 'prestasi', 'wasit', 'bola', 'kartu', 'merah', 'kuning', 'hasil'] & & \\
5 & ['nyobain', 'dagang', 'anak', 'presiden'] & Netral & 0 \\
\hline
\end{tabular}

Dilihat dari tabel di atas, contoh pertama memiliki total skor 4. Total skor tersebut didapat dari kata 'baik' yang memiliki nilai polaritas 4 . Sementara untuk kata yang lain tidak terdapat didalam 
kamus sehingga nilai polaritasnya 0 . Untuk contoh kedua memiliki total skor -5 . Skor -5 didapat dari kata'bangkrut' sementara untuk kata 'negara' dan 'pakde' tidak memiliki nilai polaritas. Untuk contoh ketiga memiliki total skor -10 . Skor -10 didapat dari kata 'buzzer' memiliki polaritas -2 , 'diam' memiliki skor -1, 'anjing' memiliki skor -4, 'melulu' memiliki skor -3. Walaupun di tweets tersebut terdapat kata 'tidak' (negating word), hal itu tidak memengaruhi nilai polaritas karena kata 'tidak' berada setelah kata yang memiliki nilai polaritas. Contoh keempat memiliki total skor 3. Total skor tersebut didapat dari kata 'baik' dengan polaritas 4, 'masalah' memilki skor -4, kata 'prestasi' memiliki skor 2. Dikarenakan terdapat kata 'lebih' (boostingword) sebelum kata yang mengandung sentimen dengan nilai polaritas 1 maka nilai polaritas semuanya dijumlahkan menjadi 3. Contoh kelima tidak memiliki nilai polaritas.

Berdasarkan hasil matching tersebut didapat sentimen positif, sentimen negatif, dan sentimen netral.

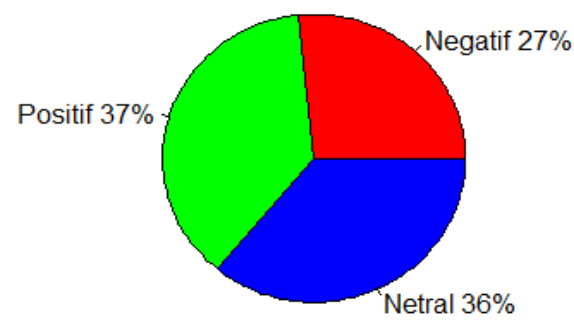

Gambar 4. Pie Chart Hasil Analisis Sentimen

Pada periode 26 September 2019-27 Oktober 2019, tweets terbanyak yaitu tweets bersentimen positif dengan 638.754 tweets. Sentimen negatif berjumlah 463.249 tweets dan sentimen netral dengan 632.982 tweets. Berdasarkan gambar diatas, bahwa secara umum tweets yang terjadi pada periode 26 September 2019-27 Oktober 2019 merupakan tweets yang bermakna baik dan positif.

Untuk melihat kesesuaian hasil analisis sentimen dengan IHSG, kurs Rupiah, dan LQ45 dilakukan cross validation (Mittal dan Goel, 2011). Cross validation yaitu membandingkan hasil analisis sentimen dengan variabel dependen berdasarkan kejadian yang signifikan. Dalam penelitian ini, terdapat 3 kejadian signifikan yaitu kejadian pasca demonstrasi terkait revisi UU KPK dan RUU KUHP pada akhir September 2019 hingga awal Oktober 2019, pelantikan presiden pada 20 Oktober 2019, dan pengumuman kabinet 2019-2024 pada 23 Oktober 2019.
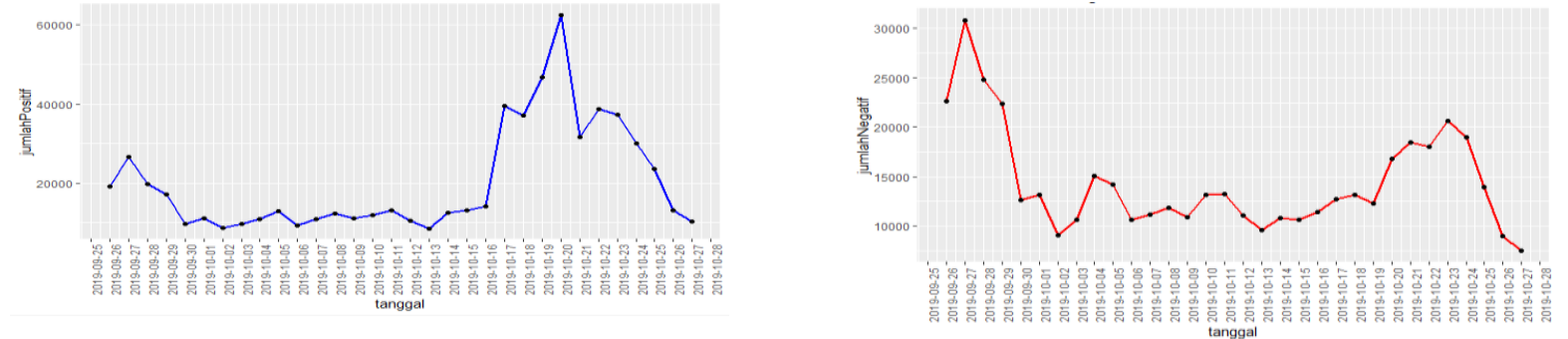

Gambar 5. Grafik Jumlah Sentimen Positif dan jumlah sentimen negatif

Sentimen positif terbanyak terjadi pada hari pelantikan presiden dengan 62.333 tweets. Hal itu menandakan bahwa pada hari itu banyak masyarakat yang mengucapkan selamat dan memberikan sentimen positif terhadap presiden. Sentimen positif paling sedikit pada tanggal 13 Oktober 2019 dengan 8.480 tweets. Pola yang terjadi pada grafik jumlah sentimen positif sesuai dengan pola yang terjadi di nilai tukar Rupiah dan indeks harga saham. Bahwa saat terjadi peningkatan jumlah tweets positif maka terjadi juga penguatan nilai tukar Rupiah dan indeks harga saham.

Sentimen negatif terbanyak terjadi pada tanggal 27 September 2019 dengan 30.988 tweets. Jumlah tersebut sangat banyak dibandingkan hari-hari lainnya dan merupakan pasca demonstrasi mahasiswa terkait revisi UU KPK dan RUU KUHP. Banyaknya tweets negatif menandakan cukup banyak masyarakat yang kurang setuju dengan revisi UU KPK dan RUU KUHP. Hal itu didukung 
dengan banyaknya hashtag bermunculan di Twitter tentang '\#hidupmahasiswa', '\#mahasiswabersatu', dan '\#turunkanjokowi'. Kejadian tersebut juga bersamaan dengan anjloknya indeks harga saham dan nilai tukar Rupiah. Sedangkan jumlah sentimen negatif paling sedikit terjadi pada 27 Oktober 2019 dengan 7.563 tweets. Jumlah sentimen negatif perlahan mulai menurun setelah pelantikan presiden hingga pengumuman kabinet.

\section{Analisis Korelasi}

Dari hasil analisis korelasi tersebut, variabel yang paling memiliki hubungan dengan data sekunder yaitu variabel ratioNP. Variabel ratioNP merupakan nilai rasio dari jumlah sentimen negatif dan jumlah sentimen positif. Saat nilai ratioNP $>1$ artinya jumlah sentimen negatif di tanggal tersebut lebih banyak dibandingkan dengan jumlah sentimen positif. Begitu juga saat nilai ratioNP $<1$ artinya jumlah sentimen negatif di tanggal tersebut lebih sedikit dibandingkan dengan jumlah sentimen positif. Sedangkan variabel independen lainnya tidak memiliki hubungan pada nilai tukar Rupiah sehingga tidak digunakan dalam penelitian ini.

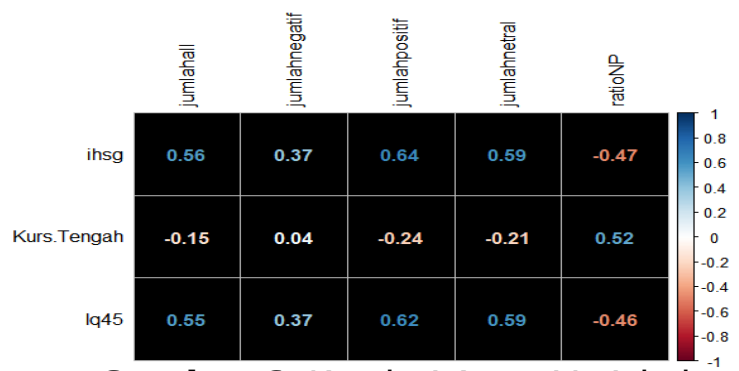

Gambar 6. Korelasi Antar Variabel

Nilai korelasi antara ratioNP dan ihsg sebesar $-0,47$. Nilai korelasi ini memiliki makna bahwa hubungan ratioNP dan IHSG cukup kuat dan memiliki arah hubungan yang tidak searah. Nilai korelasi antara variabel ratioNP dan nilai kurs sebesar 0,52. Nilai korelasi ini memiliki makna bahwa hubungan ratioNP dan nilai kurs tersebut kuat dan memiliki arah hubungan yang searah. Nilai korelasi antara variabel ratioNP dan indeks LQ45 sebesar -0,46. Nilai korelasi ini memiliki makna bahwa hubungan ratioNP dan indeks harga saham cukup kuat dan memiliki arah hubungan yang tidak searah.

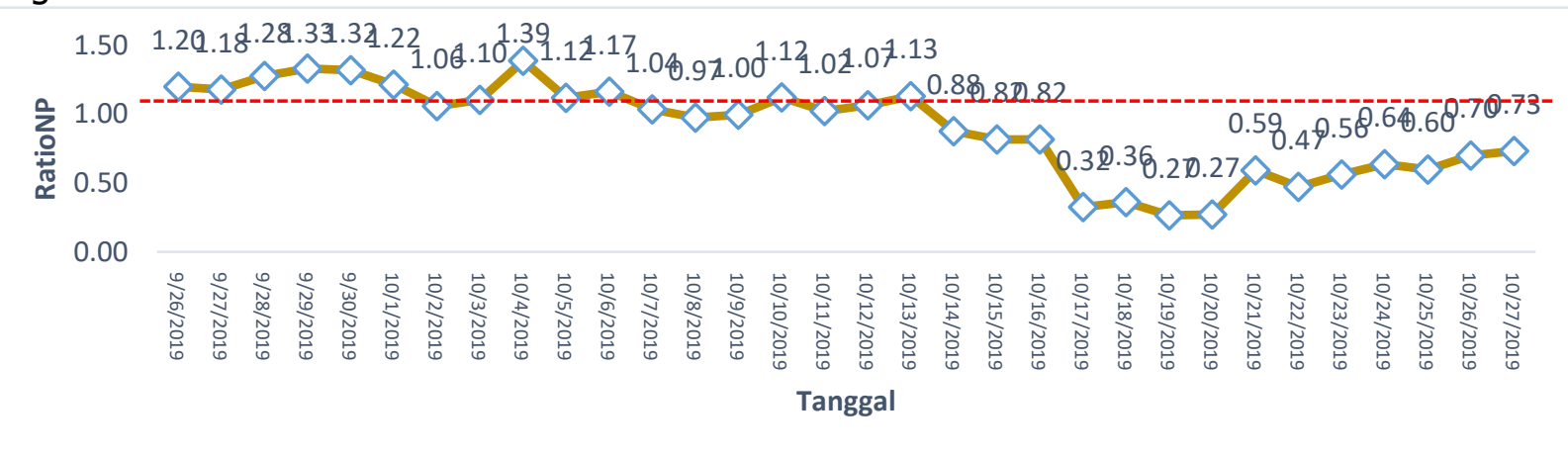

Gambar 7. Grafik variabel independen RatioNP Setiap Hari

Secara umum, ratioNP dari 9 September 2019-13 Oktober 2019 memiliki ratioNP > 1,00. Itu artinya bahwa lebih banyak sentimen negatif dibandingkan sentimen positif. Itu sesuai dengan pergerakan nilai tukar Rupiah yang terdepresiasi dan indeks harga saham yang melemah. Hal itu mengartikan bahwa saat jumlah sentimen negatif di hari itu lebih banyak dibandingkan sentimen positif mengindikasikan membuat pergerakan nilai tukar Rupiah dan indeks harga saham menjadi melemah. Tanggal 14 Oktober 2019-27 Oktober 2019, nilai ratioNP $<1,00$. Itu artinya lebih banyak sentimen positif dibandingkan sentimen negatif. Hal tersebut juga sejalan dengan kondisi kurs Rupiah yang semakin terapresiasi dan indeks harga saham yang semakin menguat. Hal itu dapat mengartikan bahwa saat jumlah sentimen positif di hari itu lebih banyak dibandingkan sentimen negatif, mengindikasikan pergerakan nilai tukar Rupiah dan indeks harga saham menjadi menguat. 


\section{Analisis Kelinieran}

Uji linieritas menggunakan Ramsey Reset Test dilakukan untuk mengetahui linieritas dari variabel dependen terhadap variabel independen terpilih. Uji linieritas digunakan sebagai petunjuk dalam memilih algoritma dan kernel machine learning yang akan digunakan. Hasilnya menunjukan bahwa ketiga variabel dependen terhadap variabel independen merupakan data yang tidak linier. Berdasarkan penelitian terkait dan didukung oleh hasil Ramsey Reset Test (ketiga model yaitu nonlinier) maka algoritma regresi machine learning yang digunakan yaitu least square support vector machine dengan kernel radial dan artificial neural network.

\section{Pemodelan dan Evaluasi}

Pemodelan menggunakan pendekatan machine learning. Algoritma yang digunakan yaitu least square support vector machine dan artificial neural network. Pemodelan dengan LSSVM menggunakan kernel radial dengan maksimum gamma 100. Pemodelan menggunakan library liquidSVM di aplikasi $\mathrm{R}$ dengan fungsi ISSVM(). Pemodelan dengan neural network dilakukan menggunakan library neuralnet di aplikasi R. Pemodelan tersebut menggunakan algoritma pembelajaran backpropagation dengan fungsi aktivasi sigmoid. Pemodelan dengan neural network multilayer perceptron dilakukan dengan 3 kombinasi hidden layer dan hidden neurons. 3 Kombinasi tersebut diantaranya menggunakan 1 hidden layer dan 1 hidden neuron (1/1/1), 2 hidden layer dan 1 hidden neuron (1/1/1/1), dan 1 hidden layer dan 2 hidden neurons (1/2/1).

Tabel 5. Hasil Evaluasi Model

\begin{tabular}{cllll}
\hline Variabel Dependen & & Metode & MAPE & RMSE \\
\hline \multirow{3}{*}{ IHSG } & LSSVM & $1,68 \%$ & 126,839 \\
& \multirow{4}{*}{ Neural Network } & $1 / 1 / 1$ & $1,62 \%$ & 111,9889 \\
& & $1 / 1 / 1 / 1$ & $2,2 \%$ & 144,569 \\
& & $1 / 2 / 1$ & $0,37 \%$ & 34,829 \\
& & LSSVM & $0,61 \%$ & 92,7098 \\
\multirow{3}{*}{ Nilai tukar Rupiah } & \multirow{3}{*}{ Neural Network } & $1 / 1 / 1$ & $0,634 \%$ & 100,447 \\
& & $1 / 1 / 1 / 1$ & $0,68 \%$ & 105,6894 \\
& & $1 / 2 / 1$ & $0,639 \%$ & 100,945 \\
& \multirow{4}{*}{ Neural Network } & LSSVM & $3,28 \%$ & 36,457 \\
& & $1 / 1 / 1$ & $2,7 \%$ & 29,693 \\
& & $1 / 1 / 1 / 1$ & $3,66 \%$ & 37,959 \\
& & $1 / 2 / 1$ & $0,92 \%$ & 11,1718 \\
\hline
\end{tabular}

Nilai MAPE dan nilai RMSE yang dihasilkan NN dengan 1 hidden layer dan 2 hidden neuron merupakan yang terkecil dalam memprediksi IHSG dan LQ45. Untuk IHSG, nilai MAPE yang dihasilkan dari algoritma tersebut yaitu $0,37 \%$. Sedangkan nilai yang dihasilkan RMSE yaitu 34,83 Rp/USD. Algoritma ini sudah cukup baik dalam memprediksi IHSG. Pemodelan ini menghasilkan nilai rata-rata MAPE dari validasi sebesar 0,7\%. Untuk LQ45, Nilai MAPE yang dihasilkan yaitu 0,92\%. Sedangkan nilai yang dihasilkan RMSE yaitu 11,1718 Rp/USD. Algoritma ini sudah cukup baik dalam mengestimasi LQ45. Pemodelan ini menghasilkan nilai rata-rata MAPE validasi sebesar 1\%. Perbedaan antara MAPE uji dan rata-rata MAPE validasi pada IHSG dan LQ45 tidak terlalu besar menunjukan bahwa model ini tidak mengalami overfitting. Berdasarkan grafik estimasi IHSG dan LQ45, menandakan bahwa terdapat pengaruh antara sentimen publik terkait situasi politik terhadap kedua variabel dependen tersebut. Hal itu dapat dilihat dari hasil estimasi sudah mendekati nilai aktual dan polanya sudah mengikuti nilai aktual. Walaupun ada beberapa hasil estimasi yang tidak berfluktuasi secara signifikan.
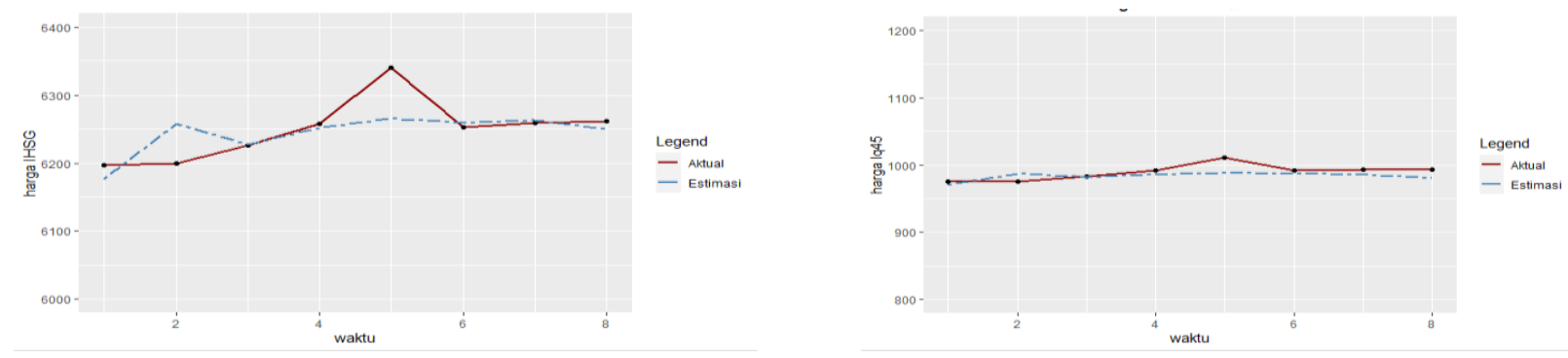
Gambar 8. Grafik Hasil Estimasi IHSG dan Hasil Estimasi LQ45

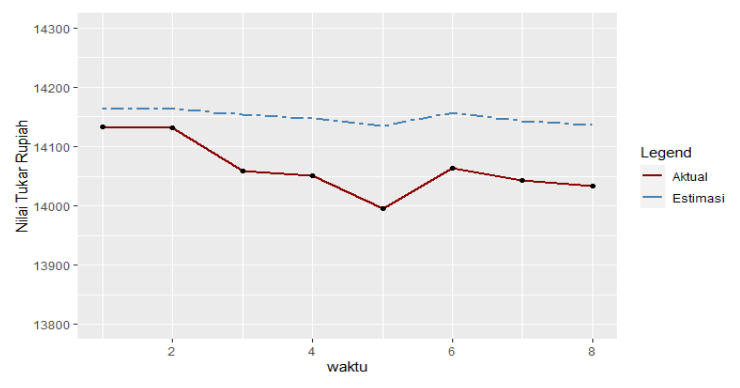

Gambar 9. Grafik Hasil Estimasi Nilai Tukar Rupiah

Nilai MAPE dan nilai RMSE yang dihasilkan model least square support vector machine merupakan yang terkecil dalam memprediksi nilai tukar Rupiah. Nilai MAPE yang dihasilkan yaitu 0,61\%. Sedangkan nilai yang dihasilkan RMSE yaitu 92,7098 Rp/USD. Algoritma ini sudah cukup baik dibandingkan ketiga model lainnya tapi belum terlalu baik karena hasil estimasi yang dihasilkan masih terlihat stagnan dan cenderung di atas nilai aktual. Ini menandakan bahwa sentimen publik tersebut tidak terlalu berpengaruh terhadap pergerakan nilai tukar Rupiah. Pemodelan nilai tukar rupiah ini menghasilkan rata-rata MAPE validasi sebesar $1 \%$. Perbedaan rata-rata MAPE validasi yang tidak terlalu jauh dengan MAPE uji menandakan model yang dihasilkan tidak overfitting.

\section{KESIMPULAN}

Berdasarkan hasil dan pembahasan diatas, dapat disimpulkan bahwa tahapan text preprocessing bermanfaat untuk mengurangi bias saat analisis sentimen. Penggunaan $k$-fold cross validation dalam pemodelan dapat membantu mengetahui overfitting dari model. Model terbaik dalam pemodelan IHSG dan LQ45 yaitu neural network dengan 1 hidden layer dan 2 hidden neurons. MAPE dan RMSE dari model IHSG yaitu 0,37\% dan 34,83 Rp/USD. Sedangkan MAPE dan RMSE dari LQ45 yaitu 0,92\% dan 11,1718 Rp/USD. Modelnya membuktikan bahwa terdapat pengaruh antara sentimen tersebut terhadap pola pergerakan IHSG dan LQ45 karena volatilitas hasil estimasi IHSG dan LQ45 cukup mengikuti pola pergerakan IHSG dan LQ45 aktual. Model terbaik dalam pemodelan nilai tukar Rupiah yaitu Least Square Support Vector Machine dengan kernel radial. MAPE dan RMSE dari nilai tukar Rupiah yaitu 0,61\% dan 92,7098 Rp/USD. Pola pergerakan estimasi nilai nilai tukar Rupiah cenderung stagnan dan jauh di atas nilai aktual. Ini membuktikan bahwa pola pergerakan nilai tukar Rupiah tidak terlalu dipengaruhi oleh sentimen publik terkait politik di Twitter.

\section{DAFTAR PUSTAKA}

APJII. (2019). Laporan Survei Penetrasi \& Profil Perilaku Pengguna Internet Indonesia. Diunduh di https://www.apjii.or.id/content/read/39/4 10/Hasil-Survei-Penetrasi-dan-PerilakuPengguna-InternetIndonesia-2018.

Ahmed, W., Bath, P., \& Demartini, G. (2017). Using Twitter as a data source: An overview of ethical, legal, and methodological challenges. Advances in Research Ethics and Integrity, 2, 79-107.

Ciaburro, G \& Venkateswaran, B (2017). Neural Network with R, Birmingham: Packt Publishing.

Ekananda, Mahyus. (2014). Ekonomi Internasional. Jakarta: Erlangga.

Kannan, S., \& Gurusamy, V. (2014). Preprocessing techniques for text mining. International Journal of Computer Science \& Communication Networks, 5(1), 7-16.

Madura, J \& Fox, R. (2011). International Financial Management ( $2^{\text {nd }}$ ed). Hampshire: Cengage Learning EMEA.

Maulana, A. (23 Maret 2016). Twitter Rahasiakan Jumlah Pengguna di Indonesia. Cnn Indonesia. 
Mittal, A., \& Goel, A. (2012). Stock prediction using twitter sentiment analysis. Standford University, CS229 $\begin{array}{lll}(2011 & \text { http://cs229. } & \text { stanford. } \\ \text { StockMarketPredictionUsingTwitterSentimentAnalysis, pdf), } 15 .\end{array}$

Nisar, T. M., \& Yeung, M. (2018). Twitter as a tool for forecasting stock market movements: A short-window event study. The journal of finance and data science, 4(2), 101-119.

Pradhypta, I. C., Iskandar, D., \& Tarumingkeng, R. C. (2018). Analisis Faktor Faktor Yang Mempengaruhi Indeks Harga Saham Gabungan Di Bursa Efek Indonesia. Jurnal Manajemen Bisnis, 13(1), 43-56.

Saputro, A., Notodiputro, K., \& Indahwati (2019). Pemodelan Pengaruh Opini Politik pada Twitter terhadap Nilai Tukar Rupiah dan Indeks Harga Saham Gabungan [Thesis]. Bogor: Institut Pertanian Bogor.

Srivastava, T. (1 Juli 2015). Difference between Machine Learning \& Statistical Modelling. AnalythicsVidhya.

Wahid, D. H., \& Azhari, S. N. (2016). Peringkasan sentimen esktraktif di twitter menggunakan hybrid TF-IDF dan cosine similarity. IJCCS (Indonesian Journal of Computing and Cybernetics Systems), 10(2), 207218.

Wang, H., \& Hu, D. (2005, October). Comparison of SVM and LS-SVM for regression. In 2005 International Conference on Neural Networks and Brain (Vol. 1, pp. 279-283). IEEE. 